\title{
Meta-Emotion and Meta-Cognition in Suicide Clinical and Critical Issues
}

Review Article

\section{Abdullah MQ*}

Professor, Clinical Psychology \& Mental Health, College of Education, University of Aleppo, Syria.

Depression is one of the most common psychological disorders. During any given year, about $15 \%$ of all adult between $18-75$ may suffer significant depressive symptoms, and one out of every 100 people with a depressive disorder dies by suicide. Suicide is the second leading cause of death for 15-34-year-old in USA (Center for Disease Control and Prevention, 2014). The following table shows the prevalence of suicide in the world [10].

Previous research suggests that, along with well-known factors including depression and past suicidal behaviors, difficulties with emotion regulation might increase the risk factor of suicide attempt [9].

Suicide typically combines three emotions: despair, guilt, anger. In other words, the person wants to dies (escape), wants to be killed (punished), and wants to hurt (punish). Where do such feelings come from? Usually they are preceded by the history of interpersonal troubles with family, in-law, or a lover or spouse. Often there are drinking problems, sexual adjustment problems, or job difficulties. The highest risk factors to suicide involve the combination: older divorced male, physically ill, substance abuser, living alone. The combination of these factors leads to severe depres- sion and preoccupation with death as the "answer" to the person suffering.

People who attempt suicide are not necessary "mentally ill", anyone may temporarily reach a state of depression severe enough to attempt suicide but the most significant factor is cognitions. It is estimated that about two thirds of all suicide attempt fall in the "to be" category. A key limitation of existing research on the link between emotions, cognitions, and behavior, however, is that it has focused almost on the self-reported use of emotion regulation and one of the most researched ways to regulate emotion is cognitive reappraisal, an antecedent-focused strategy that involves cognitive reframing of emotional stimuli in the way that augments the intensity, length and expression of an emotion [3].

Many research has been studied the emotion in suicide and depression [1]. The role of cognitive function in suicidal ideation in patients with major depressive disorder has been adequately explored. Thinking, beliefs, attitudes, perceptions and attributes play an important role in completed suicide. Suicide thoughts lead to suicide threats, and to suicide attempt and finally completed suicide. Neurocognitive deficit appear to be a risk factor of sui-

\section{Suicide rates by WHO Region in 2015 (per 100000 people)}

\begin{tabular}{|c|c|c|c|c|c|}
\hline WHO Region & $\begin{array}{c}\text { Age-standardized } \\
\text { rate }\end{array}$ & Crude rate & $\begin{array}{c}\text { Crude male } \\
\text { rate }\end{array}$ & $\begin{array}{c}\text { Crude female } \\
\text { rate }\end{array}$ & $\begin{array}{c}\text { Male - Female } \\
\text { ratio }\end{array}$ \\
\hline WHO & 10.7 & 10.7 & 13.6 & 7.8 & 1.74 \\
\hline Southeast Asia & 13.3 & 13.3 & 14.9 & 11.7 & 1.27 \\
\hline Africa & 12.8 & 7.4 & 9.9 & 4.9 & 2.01 \\
\hline Europe & 11.9 & 15.7 & 25.2 & 6.8 & 3.73 \\
\hline Western Pacific & 9.1 & 10.2 & 10.9 & 9.5 & 1.15 \\
\hline Americas & 9.1 & 9.9 & 15.2 & 4.6 & 3.27 \\
\hline Eastern Mediterranean & 4.3 & 3.9 & 5.0 & 2.7 & 1.84 \\
\hline WHO (April 2018). & \multicolumn{7}{l}{} \\
\hline
\end{tabular}

*Corresponding Author:

Dr. Mohammad Qasim Abdullah,

Professor, Clinical Psychology \& Mental Health, College of Education, University of Aleppo, Syria.

E-mail:mk.abdalah@yahoo.com 
cidal behaviors [2], and are presumed to lead to an increased risk suicide due to an incorrect appraisal of one's life situation and consequently to poor decision - making [8].

Suicidal ideation is a consistent predictor of suicide attempts and completed suicides [4]. However suicidal ideation expressed to health care providers is less frequent in older compared to younger adults, but the suicide rates in older adults are much higher than those in younger adults [5].

According to the relationship between emotion and cognition in suicide ideation and behavior, I suggest the cognitive structure that affect and be affected by emotions of suicidal behavior, on one hand, and the connection between meta-cognition and metaemotion in this behavior on the other hand.

Causal attributions are beliefs ascribing an effect to some one or more presumed caused. Causal attributions take the form of "some event $(\mathrm{Y})$ was caused by some one or more antecedent events (Ys).

Attributes or ascriptions refer to the characteristics of the person, situation or thing. Attributes or ascriptions take the form of "Some characteristics $(\mathrm{X})$ belongs to some object $(\mathrm{x})$ and is descriptive of that objects".

Expectations are beliefs regarding the probability of assurances of one or more events, given one's current state of knowledge. Expectations take the form of "some event (y) has a given likelihood of occurrence $(\mathrm{P})$, given various antecedent conditions (Xs)," The antecedent events (The Xs) may be seen as either being cause or merely incidental correlates of the consequent events (Ys).

These three types of specific cognitive contents or products can be seen to match the three area of inquiry targeted by Ross (1977) as representing the domain of interest attribution theory: causal inferences, person or situation perceptions, and the prediction of outcome or behaviors.

The other types of cognitive contents of interest include the following : Perceptions of contingency (perception of relationship between two or more situations), perception of control (perception that some individual or agency exerts a causal influence over the occurrence of some events), perception of responsibility (ascription of accountability for an event to some individual or agency, and finally, perceptions of value, attribution of worth or hedonic relevance to some event and object.

\section{Meta-Emotion v Meta-Cognition}

It is very significant to go on to the new contents or products that remain unclear in suicide specially, during adolescence. Metaemotion described as the awareness of one person's emotions (in suicide: anger, despair, and guilt), and meta-cognition describe as the awareness of one person's cognitions (in suicide: thoughts, beliefs and attributions).

The suicidal person feels helpless and decides that death is only solution. The person has narrowed all his/her options solely to death. Knowing these patterns will give some guidance in talking to a suicidal person. This person "feels" and "thought" misunder- stood. It is significant for assessing to try to accept and understand feelings "meta-emotion" and thought/attributions "metacognition" the person is expressing.

In sum, all humans (both pathological and normal) are quite fallible information-processors.

The major task for clinicians and psychotherapists is to delineate precisely "How" and "Why" people think what they think, and how pathological and normal populations differ. Theses population may differ more with respect to their cognitive and emotion contents or products and schemata than they do in the ways they process information. The major goal of cognitive and behavioral therapy is to alter the beliefs, attributions, and awareness of feelings that are presumably maintaining psychopathology in general, and suicide in special, and this may be achieved by altering the client's information-processing and awareness emotions to a more normative.

Abnormal responses to social stimuli had been described in younger people vulnerable to suicidal behavior [6], Lack of feeling connected to others and poor social problem solving [7] can amplify the risk for suicide. Szanto and colleagues reported that older suicide attempters committed significantly more errors in social emotion recognition and showed poorer global cognitive performance than elders with no psychiatric history Attempters had restricted social networks: they were less likely to talk to their children, had fewer close friends, and did not engage in volunteer activities, compared to non-suicidal depressed elders and those with no psychiatric history.

\section{References}

[1]. Bernat EM, Cadwallader M, Seo D, Vizueta N, Patrick CJ. Effects of instructed emotion regulation on valence, arousal, and attentional measures of affective processing. Dev Neuropsychol. 2011;36(4):493-518. doi: 10.1080/87565641.2010.549881. PubMed PMID: 21516545.

[2]. Gorlyn M, Keilp J, Burke A, Oquendo M, Mann JJ, Grunebaum M. Treatment-related improvement in neuropsychological functioning in suicidal depressed patients: paroxetine vs. bupropion. Psychiatry Res. 2015 Feb 28;225(3):407-12. doi: 10.1016/j.psychres.2014.12.004. PubMed PMID: 25555415.

[3]. Gross JJ, John OP. Individual differences in two emotion regulation processes: implications for affect, relationships, and well-being. J Pers Soc Psychol. 2003 Aug;85(2):348-62. PubMed PMID: 12916575.

[4]. Cukrowicz KC, Ekblad AG, Cheavens JS, Rosenthal MZ, Lynch TR. Coping and thought suppression as predictors of suicidal ideation in depressed older adults with personality disorders. Aging Ment Health. 2008 Jan;12(1):14957. doi: 10.1080/13607860801936714. PubMed PMID: 18297490.

[5]. Conwell Y, Duberstein PR, Caine ED. Risk factors for suicide in later life. Biol Psychiatry. 2002 Aug 1;52(3):193-204. PubMed PMID: 12182926.

[6]. Jollant F, Lawrence NS, Giampietro V, Brammer MJ, Fullana MA, Drapier $\mathrm{D}$, et al. Orbitofrontal cortex response to angry faces in men with histories of suicide attempts. Am J Psychiatry. 2008 Jun;165(6):740-8. doi: 10.1176/ appi.ajp.2008.07081239. PubMed PMID: 18346998.

[7]. Duberstein PR, Conwell Y, Conner KR, Eberly S, Evinger JS, Caine ED. Poor social integration and suicide: fact or artifact? A case-control study. Psychol Med. 2004 Oct;34(7):1331-7. PubMed PMID: 15697059.

[8]. McGirr A, Dombrovski AY, Butters MA, Clark L, Szanto K. Deterministic learning and attempted suicide among older depressed individuals: cognitive assessment using the Wisconsin Card Sorting Task. J Psychiatr Res. 2012 Feb;46(2):226-32. doi: 10.1016/j.jpsychires.2011.10.001. PubMed PMID: 22024486.

[9]. Rajappa K, Gallagher M, Miranda R. Emotion dysregulation and vulnerability to suicidal ideation and attempts. Cognit Ther Res. 2012 Dec 1;36(6):833-9.

[10]. World Health Organization. Suicide rates (per 100000 population): Data by WHO. 